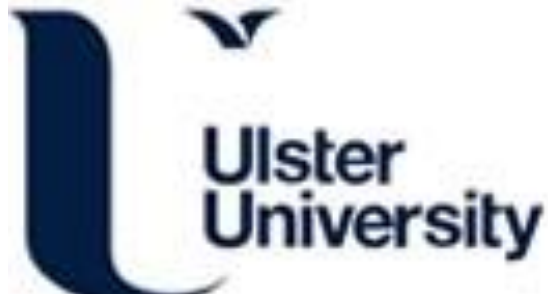

Fe catalytic growth, microstructure, and low-threshold field emission properties of open ended tubular graphite cones

Shang, NG., Papakonstantinou, P., McLaughlin, JAD., Chen, WC., Chen, LC., Chu, M., \& Stamboulis, A. (2008). Fe catalytic growth, microstructure, and low-threshold field emission properties of open ended tubular graphite cones. Journal of Applied Physics, 103(12), [124308]. https://doi.org/10.1063/1.2943265

Link to publication record in Ulster University Research Portal

Published in:

Journal of Applied Physics

Publication Status:

Published online: 23/06/2008

DOI:

10.1063/1.2943265

Document Version

Publisher's PDF, also known as Version of record

\section{General rights}

Copyright for the publications made accessible via Ulster University's Research Portal is retained by the author(s) and / or other copyright owners and it is a condition of accessing these publications that users recognise and abide by the legal requirements associated with these rights.

\section{Take down policy}

The Research Portal is Ulster University's institutional repository that provides access to Ulster's research outputs. Every effort has been made to ensure that content in the Research Portal does not infringe any person's rights, or applicable UK laws. If you discover content in the Research Portal that you believe breaches copyright or violates any law, please contact pure-support@ulster.ac.uk. 


\title{
Fe catalytic growth, microstructure, and low-threshold field emission properties of open ended tubular graphite cones
}

\author{
N. G. Shang, ${ }^{1, a)}$ P. Papakonstantinou, ${ }^{1}$ J. McLaughlin, ${ }^{1}$ W. C. Chen, ${ }^{2}$ L. C. Chen, ${ }^{2}$ \\ M. Chu, ${ }^{3}$ and A. Stamboulis ${ }^{3}$ \\ ${ }^{1}$ Nanotechnology and Integrated Bio-Engineering Centre (NIBEC), University of Ulster, Shore Road, \\ Newtownabbey, BT37 OQB, United Kingdom \\ ${ }^{2}$ Centre for Condensed Matter Sciences, National Taiwan University, Taipei 106, Taiwan \\ ${ }^{3}$ Department of Metallurgy and Materials, University of Birmingham, Edgbaston, Birmingham, B15 2TT, \\ United Kingdom
}

(Received 13 March 2008; accepted 15 April 2008; published online 23 June 2008)

\begin{abstract}
Large-area tubular graphite cones (TGCs) with an open end were successfully synthesized on Si substrates by microwave plasma assisted chemical vapor deposition using a thin Fe film as catalyst. As-grown TGCs are uniformly distributed on the Si surface with a density of $5.8 \times 10^{5} / \mathrm{cm}^{2}$ and an average growth rate of $0.6 \mu \mathrm{m} / \mathrm{min}$. Some of them are very sharp with an apex angle as small as $2^{\circ}-3^{\circ}$. Combined observations by transmission electron microscopy and cross-sectional scanning electron microscopy clarified that the TGCs possess a hollow nanotube core, a metal-free open tip and that the Fe catalyst is located in the root, strongly supporting the base-growth mechanism of TGCs. Scanning confocal micro-Raman spectroscopy along an individual TGC shows that the integrated intensity ratio of $D$ to $G$ band of individual TGC at tips (0.12) is an order of magnitude less than that at roots (1.2), confirming that the tip is highly crystalline whereas the root is of poor quality. Their field emission performance exhibits a turn-on field as low as $1.8 \mathrm{~V} / \mu \mathrm{m}$ and highly stable emission characteristics. The present study opens the way to site selective growth of TGCs and demonstrates its use as a potentially excellent emitter. (C) 2008 American Institute of Physics.
\end{abstract}

[DOI: 10.1063/1.2943265]

\section{INTRODUCTION}

Recently conical carbon nanostructures have received intensive attention from the scientific community. Many kinds of conical carbon nanostructures, such as tubular graphite cone (TGC), ${ }^{1}$ nanopipette, ${ }^{2}$ tapered carbon nanotube $(\mathrm{CNT}),{ }^{3,4}$ tubular carbon cone (TCC) ${ }^{5}$ conical carbon filament, etc., ${ }^{6,7}$ have been synthesized by means of various methods. Among them, the TGC may be more interesting as it not only has a perfectly tapered shape from several nanometers to micrometers but also has an enclosed metal-free tip with a sharp apex angle of $6^{\circ}-7^{\circ}$. Therefore, TGCs are very rigid with stable mechanical and thermal properties and are potentially excellent materials for use as high-resolution scanning probes and field emitters. ${ }^{8}$ However, most of the conical structures obtained were grown on sharp metal needles or carbon fibers, which are very like a mold for deposition. To date, TGCs have only been grown on sharp Fe needles, planar steel substrates, and $\mathrm{Fe}$ catalytic carbon spherules with a $100 \mu \mathrm{m}$ size. ${ }^{1,8,9}$ Those bulk (needles and steel) materials inevitably contain various impurities, which could diffuse onto surface at high temperature and catalytically grow TGCs. The use of purely thin Fe film could benefit not only to confirm the Fe catalytic growth model of TGCs suggested but also to allow position-selective and patterning control growth alike in CNTs. The growth of TGCs and other conical structures on a $\mathrm{Si}$ substrate will be more

\footnotetext{
a) Author to whom correspondence should be addressed. Electronic mail: ngshang@hotmail.com
}

attractive, because this not only will allow the comprehensive investigation of their growth mechanism, based on the noncatalytic nature of $\mathrm{Si}$, but also will permit their direct integration into currently developed Si-based semiconductor products (for example, the Si cantilever of scanning tunneling microscopy). Moreover, tubular nanostructures with an open end will be more interesting not only for improved electron emission but also for the drug delivery. However, both properties are not clear for TGCs yet. In this paper, we reported the growth of large-area TGCs with an open end on the Si substrate by microwave plasma assisted chemical vapor deposition (MPCVD) using a thin Fe film as the catalyst source. The morphology and structure of TGCs were characterized by scanning electron microscopy (SEM), transmission electron microscopy (TEM), and Raman scattering spectroscopy, respectively. The field electron emission of TGCs was investigated using a parallel-plate diode configuration.

\section{EXPERIMENTAL}

A $10 \times 10 \mathrm{~mm}^{2}$ sized Si wafer was ultrasonically cleaned sequentially by acetone, ethanol, and de-ionized water for several minutes. Then a layer of $10 \mathrm{~nm} \mathrm{SiO}$ and a layer of $20 \mathrm{~nm}$ Fe thin films were in turn deposited on the cleaned $\mathrm{Si}$ by magnetic sputtering. The Fe film served as catalyst, while the $\mathrm{SiO}_{2}$ film acted as a buffer layer to prevent the diffusion of $\mathrm{Fe}$ into the $\mathrm{Si}$ substrate during the high-temperature growth of TGCs in a $2.45 \mathrm{GHz}, 1.5 \mathrm{~kW}$ MPCVD system. After pumped down to a base pressure of $7.5 \times 10^{-3}$ torr, the 

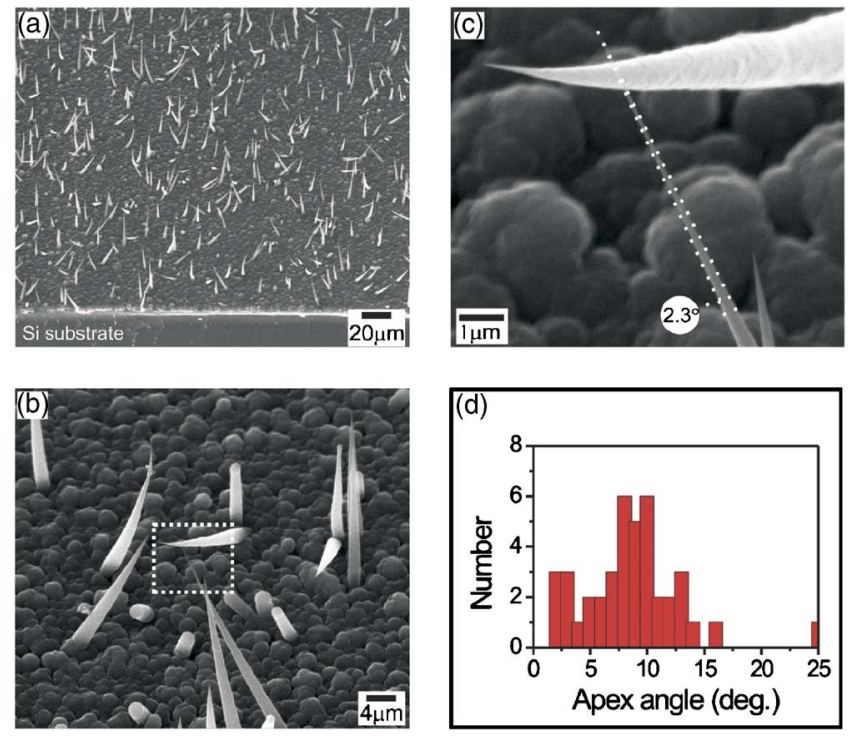

FIG. 1. (Color online) [(a)-(c)] Different magnification SEM image of TGCs observed at a tilt angle of $35^{\circ}$. The sharpest TGC has an apex angle as small as $2.3^{\circ}$ (c); (d) the distribution of straight TGC's apex angle.

chamber was loaded by a gas mixture of 20 SCCM (SCCM denotes cubic centimeter per minute at STP) $\mathrm{H}_{2}$ and $80 \mathrm{SCCM} \mathrm{N}_{2}$ and kept at a pressure of 40 torr. Plasma was ignited by a microwave power of $1 \mathrm{~kW}$ to pretreat the substrate for $15 \mathrm{~min}$. Then, a $20 \mathrm{SCCM} \mathrm{CH}_{4}$ flow replaced the $\mathrm{H}_{2}$ gas and the microwave power was increased to $1.1 \mathrm{~kW}$ for initiating the growth of TGCs. During the whole process, the substrate was heated by a high-frequency induction coil up to $950-1000{ }^{\circ} \mathrm{C}$, as measured by an infrared optical pyrometer from a top window of the chamber.

The TGCs were scratched from the Si wafer onto a holy carbon coated $\mathrm{Cu}$ grid and then observed by a $200 \mathrm{keV}$ TEM. The structural variation of individual TGCs was characterized by confocal micro-Raman with a spatial resolution of $1 \mu \mathrm{m}$ and an excitation source of $633 \mathrm{~nm}$, at room temperature. The field emission properties of TGCs were investigated at a base pressure of $2 \times 10^{-6}$ torr using a parallelplate diode configuration with a spacing of about $90 \mu \mathrm{m}$ between the sample and the anode, which is made of an indium tin oxide $\left(2 \times 2 \mathrm{~mm}^{2}\right)$ patterned glass. A small amount of carbon paste was positioned on the top corner of the sample to provide intimate contact between the sample surface and the cathode holder.

\section{RESULTS AND DISCUSSION}

After deposition for $30 \mathrm{~min}$, a layer of gray material was deposited on the Si substrate. TGCs were found to uniformly distribute in the most areas of the $\mathrm{Si}$ substrate except for some treelike carbon structures and a few carbon nanoflake coated TGCs in the outmost edge area. Figure 1(a) presents a typical SEM image taken from the sample at a tilting angle of $35^{\circ}$. The straight and sharp TGCs are dominated in the product but some bent hornlike TGCs and shortly stubby rods sporadically exist. These as-deposited TGCs have an average length of about $18-20 \mu \mathrm{m}$ and a density of 5.8 $\times 10^{5} / \mathrm{cm}^{2}$. A few TGCs reach $27 \mu \mathrm{m}$ long. The growth rate of TGCs on $\mathrm{Si}$ substrates was calculated as $0.6-0.7 \mu \mathrm{m} / \mathrm{min}$, faster than that on Fe needles and planar steel substrates. Figure 1(b) is a typical higher magnification SEM image, revealing that the as-grown most TGCs have different shapes, caps, and apex angles except for a few TGC with straight CNT tips. ${ }^{8,9}$ The straight TGCs were found to have a wide range of apex angles between $2^{\circ}$ and $25^{\circ}$, as shown in Fig. 1(d). The average apex angle is about $8^{\circ}-10^{\circ}$. Figure 1(c) is an enlarged image of the marked area in Fig. 1(b), showing a TGC with an apex angle of $2.3^{\circ}$, much smaller than the conical carbon structures previously reported. ${ }^{1,2,5,10}$ In addition, the majority of TGCs were found to be very rough on the whole surface except for the tip area. They seem to be made of many tiny particles, different from previously reported TGCs, which had a faceted and helical morphology except for their root area.

The location of catalysts in nanostructures is critical not only for the investigation of the growth mechanism but also for the material properties. Figure 2(a) shows a lowresolution TEM image of an individual TGC. The TGC has an approximately $400 \mathrm{~nm}$ thick base and a $50 \mathrm{~nm}$ thick tip. As observed by SEM, the surface of TGCs is not smooth and some sections are surrounded by a few amounts of thin carbon nanoflakes. Figure 2(b) shows the high-resolution TEM image of the TGC tip. The inner diameter of the TGC is about $20 \mathrm{~nm}$. The tip is open and partially covered by a layer of amorphous carbon. Energy dispersive x-ray spectroscopy (EDS) was used to analyze the chemical composition, as shown in the inset of Fig. 2(a). The TGC mainly consists of carbon and some oxygen adsorbates due to the sample exposure to air. No any other metals were found on the tip except for element $\mathrm{Cu}$ from the grid used.

To further identify the location of the Fe catalyst, the cross section of the sample between the TGC and the $\mathrm{Si}$ substrate was examined using SEM. Figures 3(a) and 3(b) are cross-sectional SEM images of the TGC sample. At the $\mathrm{Si} / \mathrm{TGC}$ interface, there is an approximately $4 \mu \mathrm{m}$ thick layer, from which sharp TGCs stemmed, looking very similar to bamboos coming out from the earth. No distinct layers of $\mathrm{SiO}_{2}$ and $\mathrm{Fe}$ were found. The EDS measurement shows that the underneath thick layer at the TGC root mainly consists of carbon (86.6 at. \%), Si ( 13.2 at. \%), and small amounts of $\mathrm{Fe}(\sim 0.2$ at. \%) whereas no traces of Fe catalyst were found along the TGCs [see Fig. 3(c)]. It is worth noting that the EDS traces along the TGC contained less than 5 at. \% Si, which could originate from the $\mathrm{Si}$ substrate during the high-temperature growth. Figure 3(b) shows two broken TGCs lying on the surface. One of them was broken from its root with a clear cross section, where we surprisingly found a residual CNT in the center being connected with the thick underneath carbon layer. Central nanotubes also emerged from TGCs broken in the middle. This finding clearly indicates that the interior throughout the whole TGC is hollow like that of CNTs and is not limited only in the sharp tip that we were able to detect by TEM. Therefore, we have demonstrated that TGCs possess a hollow core throughout their length from bottom to their tip. The fact that the $\mathrm{Fe}$ catalyst is located in the root rather than the tip of TGCs unequivocally supports the Fe catalytic base-growth mecha- 

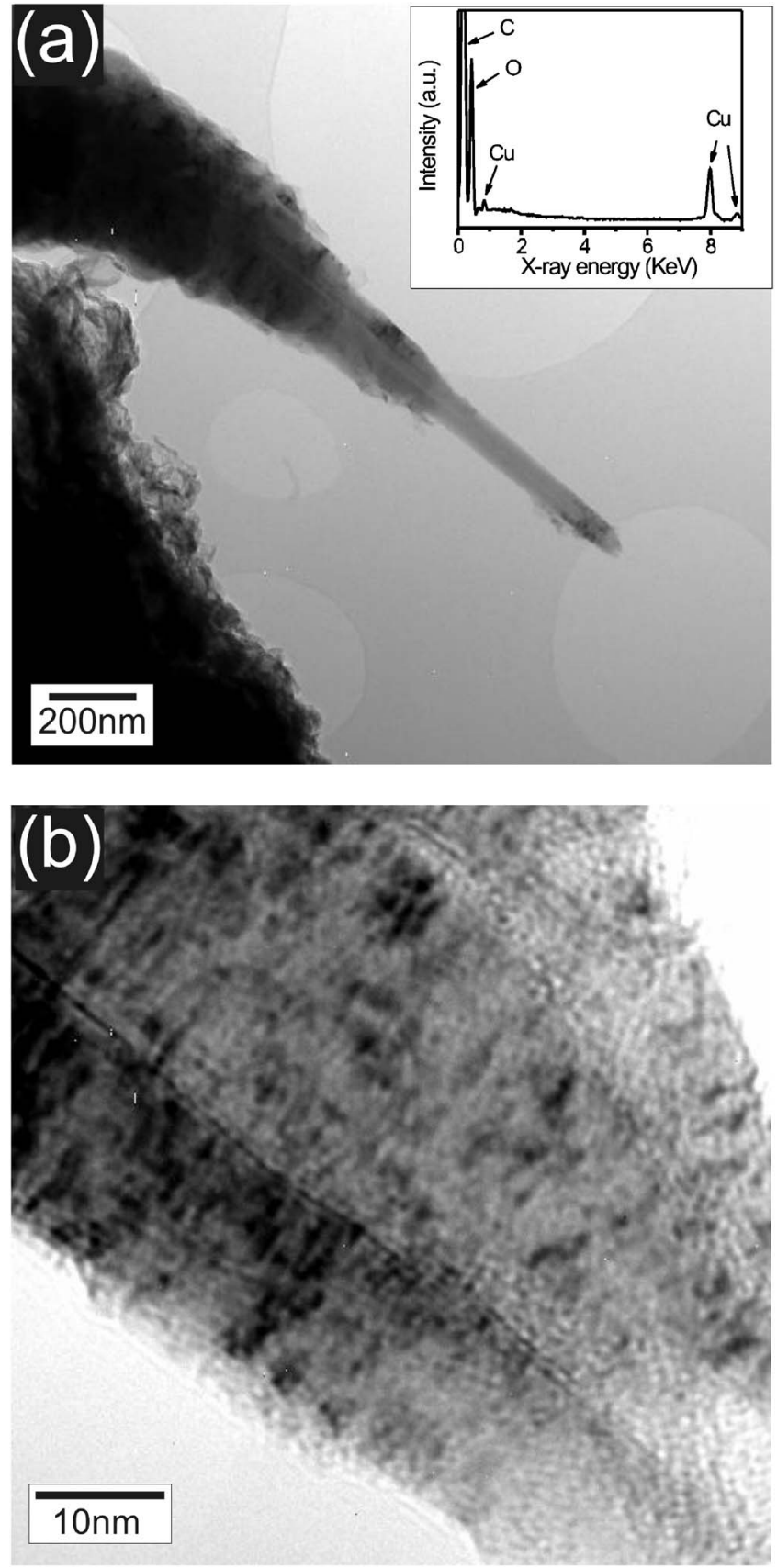

FIG. 2. (a) Low-resolution TEM image of single TGC, (b) high-resolution TEM image of the TGC tip; the inset of (a) is an EDS spectrum of the TGC.

nism of TGCs we suggested previously, ${ }^{8,9}$ where the growth of TGCs is possibly due to either the increasing of the catalyst size or the gradual extension of the boundary diffusion interlayer of the solid-liquid around the catalyst surface. The present study could open the way to control the growth of TGCs in well defined positions using a patterned Fe film.

Figure 4(a) shows typical Raman spectra over a wave number range from 1000 to $1800 \mathrm{~cm}^{-1}$ taken from different areas along a tilted $20 \mu \mathrm{m}$ long TGC. All spectra display a strong peak with comparable intensities at $1582 \pm 2 \mathrm{~cm}^{-1}$, corresponding to the $G$ band of microcrystalline graphite, and another peak with quite different intensities at $1332 \pm 2 \mathrm{~cm}^{-1}$, corresponding to the $D$ band of graphite. The intensity of the $D$ band significantly increases from the tip to the root. The integrated intensity ratios $\left(I_{D} / I_{G}\right)$ of $D$ to $G$
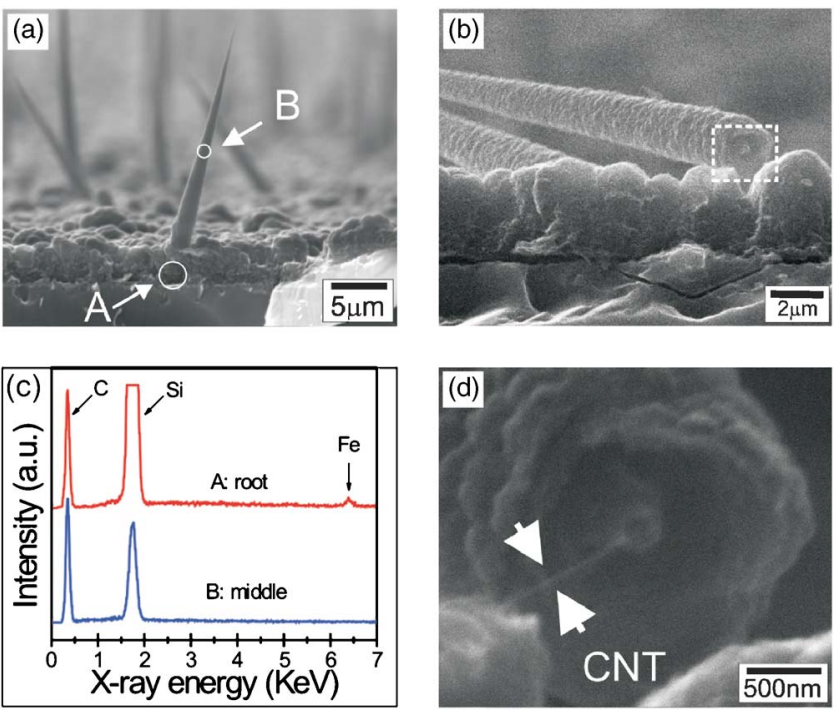

FIG. 3. (Color online) [(a) and (c)] Cross-sectional SEM image of the TGC sample; (c) EDS spectra taken from the root and middle of individual TGCs shown in (a); (d) enlarged image of the marked area in (b), showing a CNT in the TGC.

bands taken from the root, middle, and tip areas of TGCs are $1.2 \pm 0.01,0.78 \pm 0.01$, and $0.12 \pm 0.01$, respectively. The ratio from the TGC tip is very similar to that of the TGCs on steel substrates. In addition, at both the root and the middle there is a $D^{\prime}$ shoulder at $1616 \pm 2 \mathrm{~cm}^{-1}$, which is absent at
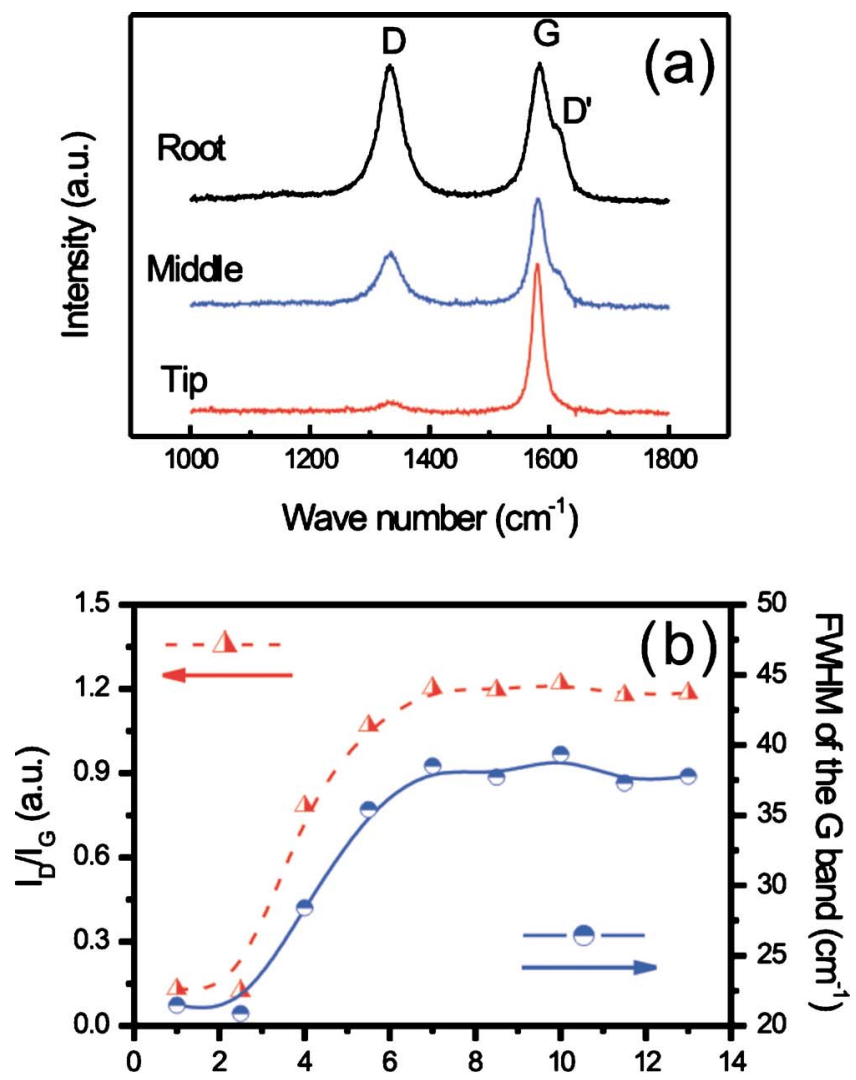

Distance from the tip to the root of a TGC $(\mu \mathrm{m})$

FIG. 4. (Color online) (a) Typical Raman spectra of different areas of a single TGC; (b) the $I_{D} / I_{G}$ and FWHM of $G$ band as a function of distance from the tip to the root, showing the highly crystalline tip and poor-quality root. 


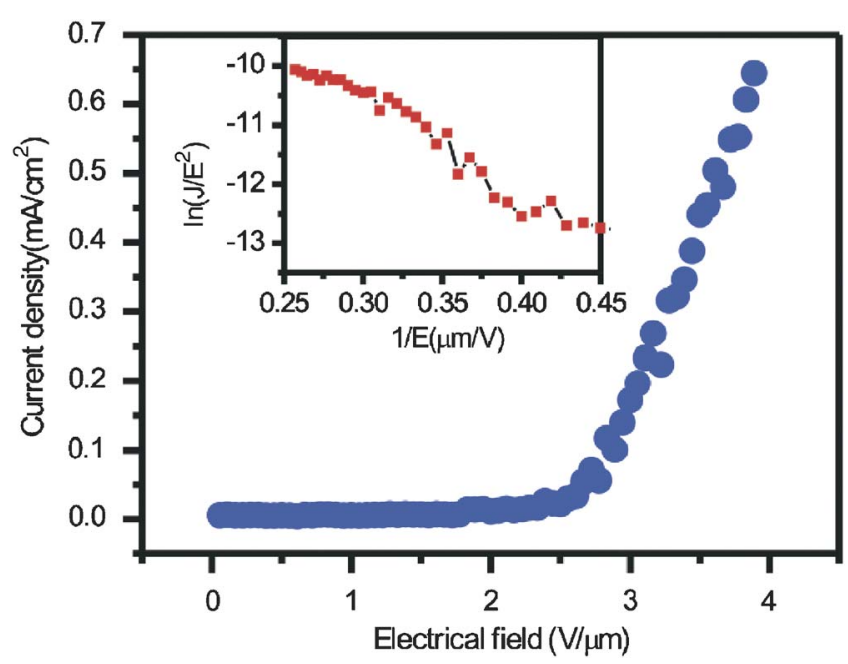

FIG. 5. (Color online) Emission current density vs the applied electric field of TGCs and corresponding FN plot (inset).

the tip. Figure 4(b) shows the $I_{D} / I_{G}$ and full width at half maximum (FWHM) of $G$ band as a function of the distance from the tip to the root along the single TGC. The FWHM of $G$ band as another fingerprint of crystalline quality for carbon materials has the same trend as the $I_{D} / I_{G}$. All of the spectral features convincingly indicate that the tip is highly crystalline and graphitized while the root is more disordered and of poor quality, as both the $D$ and $D^{\prime}$ bands are induced by disordered carbon. ${ }^{11}$ This is in reasonable agreement with the surface morphology of the TGCs, which seems to be made of many granules except for the tip.

Figure 5 shows the relation of emission current density versus the applied electric field of TGCs based on the measurement of 10 cycles. Almost consistent curves of the 10 cycles reveal the highly stable and reproducible field emission of TGCs. The turn-on field (defined at the current density of $0.01 \mathrm{~mA} / \mathrm{cm}^{2}$ ) was found to be $1.8 \mathrm{~V} / \mu \mathrm{m}$, which is less than that of the majority of as-grown and post-treated vertically aligned CNTs, with a turn-on field of 2-4 V/ $/ \mathrm{m}^{12-14}$ The lower turn-on field of TGCs could be assigned to either the open end or their lower density, which can effectively depress the screen effect by lowering the interaction between tips. However, this turn-on field is higher than that of TCCs and highly aligned CNTs due to the poor alignment of the TGCs. ${ }^{5,15}$ According to the classic model of electron field emission, ${ }^{16}$ Fowler-Nordheim (FN) plots are shown in the inset of Fig. 5. The almost linear curve indicates that the field emission of TGCs is based on the barrier tunneling field emission mechanism. Using the slope $\left(B \phi^{3 / 2} / \beta, B=6.87 \times 10^{9} \mathrm{~V} \mathrm{~m}^{-1} \mathrm{eV}^{-3 / 2}\right)$ of the FN plot and a work function $(\phi)$ of $5.0 \mathrm{eV}$ for the TGC, the field enhancement factor $(\beta)$ was calculated to have a value of 3700 , which is nine to ten times larger than the geometrical factor $\left(\beta^{\prime}=h / r\right)$, which can be simply determined from the height $(18-20 \mu \mathrm{m})$ and radius $(\sim 50 \mathrm{~nm})$ of the tip. The large difference between the electrically measured $\beta$ and geometrical $\beta^{\prime}$ has also been observed from vertically aligned CNT forests but not from precisely defined CNT arrays. ${ }^{12,17}$ A critical reason for this discrepancy could be attributed to the pres- ence of a high concentration of surface adsorbates, due to the poor vacuum during the measurement. They were speculated to induce a non-FN emission, as can be evidenced by the imperfect linearity of FN plots. ${ }^{18,19}$

\section{CONCLUSION}

Fe films were used as catalysts to successfully obtain large-area, open ended TGCs on the Si substrate by MPCVD. The density of TGCs and average growth rate are 5.8 $\times 10^{5} / \mathrm{cm}^{2}$ and $0.6 \mu \mathrm{m} / \mathrm{min}$, respectively. The sharpest TGC was found to have an apex angle down to $2.3^{\circ}$. The Fe catalyst was only found in the root of TGCs, proving the basegrowth mechanism. The one-order-magnitude variation in the integrated intensity ratio of $D$ to $G$ bands along the TGC axis in Raman spectra reveals that the tip is highly crystalline and the root is of poor quality in accordance with its granular surface morphology. The field emission of the TGCs was investigated by a parallel-plate configuration and shows a good emission property with the turn-on field as low as $1.8 \mathrm{~V} / \mu \mathrm{m}$ and the field enhancement factor up to 3700 . Our results make possible not only to control the growth of TGCs in a selective site but also to apply TGCs potentially for the cold cathode and drug delivery.

\section{ACKNOWLEDGMENTS}

The authors acknowledge the European Union under the DESYGN-IT project (STREP Project No. 505626-1), the Royal Society in UK, and the Ministry of Education in Taiwan (Taiwan-UK Joint Project).

${ }^{1}$ G. Y. Zhang, X. Jiang, and E. G. Wang, Science 300, 472 (2003).

${ }^{2}$ R. C. Mani, X. Li, M. K. Sunkara, and K. Rajan, Nano Lett. 3, 671 (2003).

${ }^{3}$ G. Bhimarasetti, M. K. Sunkara, U. M. Graham, B. H. Davis, C. Suh, and K. Rajan, Adv. Mater. (Weinheim, Ger.) 15, 1629 (2003).

${ }^{4}$ J. Q. Hu, Y. Bando, J. H. Zhan, C. Y. Zhi, F. F. Xu, and D. Golberg, Adv. Mater. (Weinheim, Ger.) 18, 197 (2006).

${ }^{5}$ J. J. Li, C. Z. Gu, Q. Wang, P. Xu, Z. L. Wang, Z. Xu, and X. D. Bai, Appl. Phys. Lett. 87, 143107 (2005).

${ }^{6}$ W. Xia, D. S. Su, R. Schlögl, A. Birkner, and M. Muhler, Adv. Mater. (Weinheim, Ger.) 17, 1677 (2005).

${ }^{7}$ V. I. Merkulov, M. A. Guillorn, D. H. Lowndes, and M. L. Simpson, Appl. Phys. Lett. 79, 1178 (2001).

${ }^{8}$ N. G. Shang, W. I. Milne, and X. Jiang, J. Am. Chem. Soc. 129, 8907 (2007).

${ }^{9}$ N. G. Shang and X. Jiang, Appl. Phys. Lett. 87, 163102 (2005).

${ }^{10}$ A. Krishnan, E. Dujardin, M. M. J. Treacy, J. Hugdahl, S. Lynum, and T. W. Ebbesen, Nature (London) 388, 451 (1997).

${ }^{11}$ S. Reich and C. Thomsen, Philos. Trans. R. Soc. London, Ser. A 362, 2271 (2004).

${ }^{12}$ M. Chhowalla, C. Ducati, N. L. Rupesinghe, K. B. K. Teo, and G. A. J. Amaratunga, Appl. Phys. Lett. 79, 2079 (2001).

${ }^{13}$ N. G. Shang, C. P. Li, W. K. Wong, C. S. Lee, I. Bello, and S. T. Lee, Appl. Phys. Lett. 81, 5024 (2002).

${ }^{14}$ B. Q. Zeng, G. Y. Xiong, S. Chen, W. Z. Wang, D. Z. Wang, and Z. F. Ren, Appl. Phys. Lett. 89, 223119 (2006).

${ }^{15}$ H. Murakami, M. Hirakawa, C. Tanaka, and H. Yamakawa, Appl. Phys. Lett. 76, 1776 (2000).

${ }^{16}$ R. H. Fowler and L. Nordheim, Proc. R. Soc. London, Ser. A 119, 193 (1928).

${ }^{17}$ S. M. C. Vieira, K. B. K. Teo, W. I. Wilne, O. Groning, L. Gangloff, E. Minoux, and P. Legagneux, Appl. Phys. Lett. 89, 022111 (2006).

${ }^{18}$ K. A. Dean and B. R. Chalamala, Appl. Phys. Lett. 76, 375 (2000).

${ }^{19}$ V. Semet, Y. T. Binh, P. Vincent, D. Guillot, K. B. K. Teo, M. Chhowalla, G. A. J. Amaratunga, W. I. Milne, P. Legagneux, and D. Pribat, Appl. Phys. Lett. 81, 343 (2002). 